\title{
Canine Acanthomatous Epulis
}

National Cancer Institute

\section{Source}

National Cancer Institute. Canine Acanthomatous Epulis. NCI Thesaurus. Code C134956.

A tumor arising from odontogenic epithelium and occurs in a dog. 